\title{
The evaluation of long-term screw pull-out rates following posterior thoracolumbar fusion surgery with short and thin pedicle screws
}

\author{
Umit Kocaman ${ }^{1}$, Hakan Yilmaz ${ }^{2}$ \\ ${ }^{1}$ Izmir Cigli Region Education and Research Hospital, Department of \\ Neurosurgery, Izmir, TURKEY \\ 2 University of Healt Sciences Izmir Bozyaka Education and Research \\ Hospital, Department of Neurosurgery, Izmir, TURKEY
}

\begin{abstract}
Background. The aim of this study was to evaluate screw pull-out rates after fusion operations with short and thin pedicle screws.

Methods. A total of 200 posterior lumbar and thoracolumbar fusion operations performed at our clinic with short and thin pedicle screws $(5.5 \times 35 \mathrm{~mm})$ were retrospectively evaluated. The patients were assessed with computed tomography postoperatively on the day of surgery and at the 6th month. Single groove retraction of the transpedicular screw was evaluated as pull-out. The results were evaluated by the 'number of pull-out cases / total number of cases' and also the 'total number of pull-out screws / total number of screws used' ratios.

Results. There were $112(56 \%)$ female and 88 (44\%) male patients with a mean age of 58 years. The total number of screws used in the 200 cases was 1188 . There were $88(7.4 \%)$ thoracic pedicle screws, $1056(88.9 \%)$ lumbar pedicle screws and $44(3.7 \%)$ sacral pedicle screws used. No pull-out was found in the control CTs taken postoperatively. Left side T11 and T12 pull-out was observed in one case and left L4 pull-out was observed in another case in the control CTs taken at the postoperative 6th month. Pull-out was observed in $2(1 \%)$ of the 200 cases and $3(0.25 \%)$ of the 1188 screws.

Conclusions. All the short and thin pedicle screws used had passed the pedicle length and neurocentral junction. The use of a $5.5 \times 35 \mathrm{~mm}$ screws in fusion operations is less invasive than using longer and thicker screws while the pull-out rates may be similar.
\end{abstract}

\section{INTRODUCTION}

Posterior lumbar and thoracolumbar fusion operations constitute an important part of neurosurgery practice. The major problems after these operations are screw pull-out, adjacent segment degeneration, deterioration of instrumentation integrity, and fusion insufficiency. Various preventive measures such as post-cement screw application and porous coated screw application are rarely used to prevent screw pull-out, while the tendency is to use long and thick screws. The general

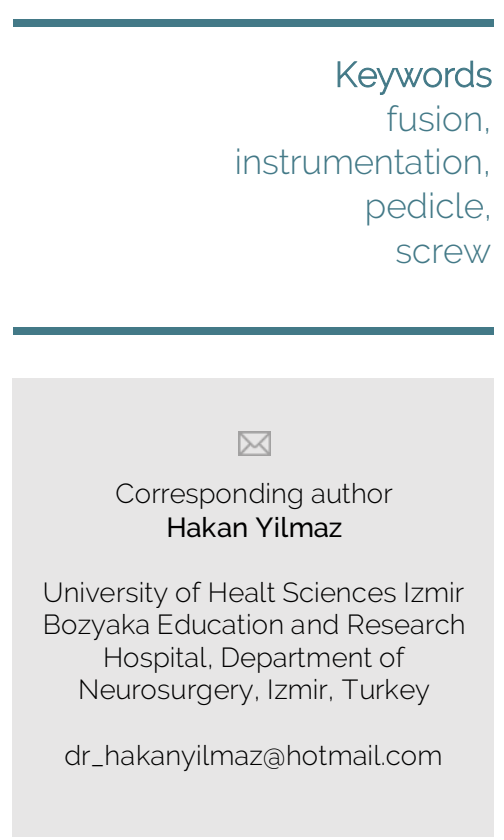

Copyright and usage. This is an Open Access article, distributed under the terms of the Creative Commons Attribution Non-Commercial No Derivatives License (https://creativecommons .org/licenses/by-nc-nd/4.0/) which permits noncommercial re-use, distribution, and reproduction in any medium, provided the original work is unaltered and is properly cited.

The written permission of the Romanian Society of Neurosurgery must be obtained for commercial re-use or in order to create a derivative work.

ISSN online 2344-4959

(C) Romanian Society of Neurosurgery

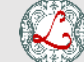

First published June 2019 by London Academic Publishing www.lapub.co.uk 
preference is to use $6.5 \times 45 \mathrm{~mm}, 6.5 \times 50 \mathrm{~mm}, 6.0 \times 45$ $\mathrm{mm}, 6.0 \times 50 \mathrm{~mm}$ screws for the lumbar and thoracolumbar junction. Screws $7.0 \mathrm{~mm}$ thick or 55 $\mathrm{mm}$ long are also in use for the lumbar region. Although long and thick screw applications increase spine stability, they also create surgical risk $[2,4,12]$.

We investigated the pull-out rates in the cases where we used screws that were shorter and thinner than those generally used in thoracolumbar fusion operations. We would like to share our experiences on surgical safety in posterior lumbar and thoracolumbar fusion surgeries in this regard.

\section{MetHODS}

A total of 200 posterior lumbar and thoracolumbar fusion operations performed with short and thin pedicle screws between 2016 and 2018 at the Izmir Cigli Regional Training Hospital's Neurosurgery Department were evaluated retrospectively. This evaluation was performed only in patients who underwent posterior segmental instrumentation and fusion with $5.5 \times 35 \mathrm{~mm}$ transpedicular screws. Cases where screws of a different size were used as necessary and those that required revision for postoperative screw malposition were not included in the study. An evaluation was made with preoperative $\mathrm{CT}$ in all cases and a screw length of 35 $\mathrm{mm}$ was used after it was deemed to be adequate to reach the neurocentral junction. The patients were evaluated with computed tomography postoperatively on the day of surgery and at the 6th month. Single groove retraction of the transpedicular screw was evaluated as pull-out. The results were evaluated by the 'number of pull-out cases / number of cases' and the 'total number of pull-out screws / total number of screws' ratios.

\section{STATISTICAL ANALYSIS}

Descriptive statistical methods were used in the evaluation of the data. The results were expressed as mean \pm standard deviation and frequency (\%).

\section{RESULTS}

The 200 patients included in the study consisted of 112 (56\%) females and 88 (44\%) males. The mean age was 58 years and the age range was 22-78 years. The primary pathology was narrow lumbar canal in 100 cases, lumbar spondylolisthesis (grade 1) in 26 cases, degenerative type lumbar spondylolisthesis (grade 1) in 24 cases, post-traumatic burst fracture requiring posterior thoracolumbar fusion in 22 cases, post-traumatic burst fracture requiring posterior lumbar fusion in 6 cases and primary or recurrent lumbar disc hernia with segmental instability in 22 cases (TABLE 1). The number of screws used in the 200 cases was 1188 . These consisted of 88 (7.4\%) thoracic pedicle screws, 1056 (88.9\%) lumbar pedicle screws and 44 (3.7\%) sacral pedicle screws (TABLE 2). No pull-out was found in any patient on the control CTs taken the same day postoperatively (FIGURE 1,2). Left T11 and T12pull-out was observed in control CTs performed at the postoperative 6th month in 1 case who had undergone thoracolumbar fusion (FIGURE 3). Left L4 pull-out was observed in 1 patient who had undergone surgery due to narrow lumbar canal. Both patients underwent revision surgery. Pull-out was therefore observed in $2(1 \%)$ of the 200 cases and $3(\% 0.25)$ of the 1188 screws.

\begin{tabular}{|l|l|l|l|}
\hline Pathology & Female & Male & Total \\
\hline narrow lumbar canal & 59 & 41 & 100 \\
\hline $\begin{array}{l}\text { isthmic type lumbar } \\
\text { spondylolisthesis } \\
\text { (grade 1) }\end{array}$ & 13 & 13 & 26 \\
\hline $\begin{array}{l}\text { degenerative type } \\
\text { lumbar } \\
\text { spondylolisthesis } \\
\text { (grade 1) }\end{array}$ & 13 & 11 & $\mathbf{2 4}$ \\
\hline $\begin{array}{l}\text { burst fracture } \\
\text { requiring } \\
\text { thoracolumbar fusion }\end{array}$ & 12 & 10 & $\mathbf{2 2}$ \\
\hline $\begin{array}{l}\text { lumbar disc herniation } \\
\text { with segmental } \\
\text { instability }\end{array}$ & 12 & 10 & $\mathbf{2 2}$ \\
\hline $\begin{array}{l}\text { burst fracture } \\
\text { requiring posterior } \\
\text { lumbar fusion }\end{array}$ & 3 & 3 & 6 \\
\hline Total & 112 & 88 & $\mathbf{2 0 0}$ \\
\hline
\end{tabular}

TABLE 1. The distribution of the cases where short and thin pedicle screws were applied according to the primary pathology and gender.

\begin{tabular}{|l|l|l|l|}
\hline Pathology & $\begin{array}{l}\text { Lumbar } \\
\text { pedicle } \\
\text { screw }\end{array}$ & $\begin{array}{l}\text { Thoracic } \\
\text { pedicle } \\
\text { screw }\end{array}$ & $\begin{array}{l}\text { Sacral } \\
\text { pedicle } \\
\text { screw }\end{array}$ \\
\hline $\begin{array}{l}\text { narrow lumbar } \\
\text { canal }\end{array}$ & 558 & 0 & 12 \\
\hline $\begin{array}{l}\text { isthmic type } \\
\text { lumbar } \\
\text { spondylolisthesis } \\
\text { (grade 1) }\end{array}$ & 66 & 4 & 14 \\
\hline
\end{tabular}




\begin{tabular}{|l|l|l|l|}
\hline $\begin{array}{l}\text { degenerative } \\
\text { type lumbar } \\
\text { spondylolisthesis } \\
\text { (grade 1) }\end{array}$ & 206 & 6 & 8 \\
\hline $\begin{array}{l}\text { burst fracture } \\
\text { requiring } \\
\text { thoracolumbar } \\
\text { fusion }\end{array}$ & 130 & 78 & 0 \\
\hline $\begin{array}{l}\text { lumbar disc } \\
\text { herniation with } \\
\text { segmental } \\
\text { instability }\end{array}$ & 54 & 0 & 6 \\
\hline $\begin{array}{l}\text { burst fracture } \\
\text { requiring } \\
\text { posterior lumbar } \\
\text { fusion }\end{array}$ & 42 & 0 & 4 \\
\hline Total & 1056 & 88 & 44 \\
\hline
\end{tabular}

TABLE 2. The distribution of the screws used.
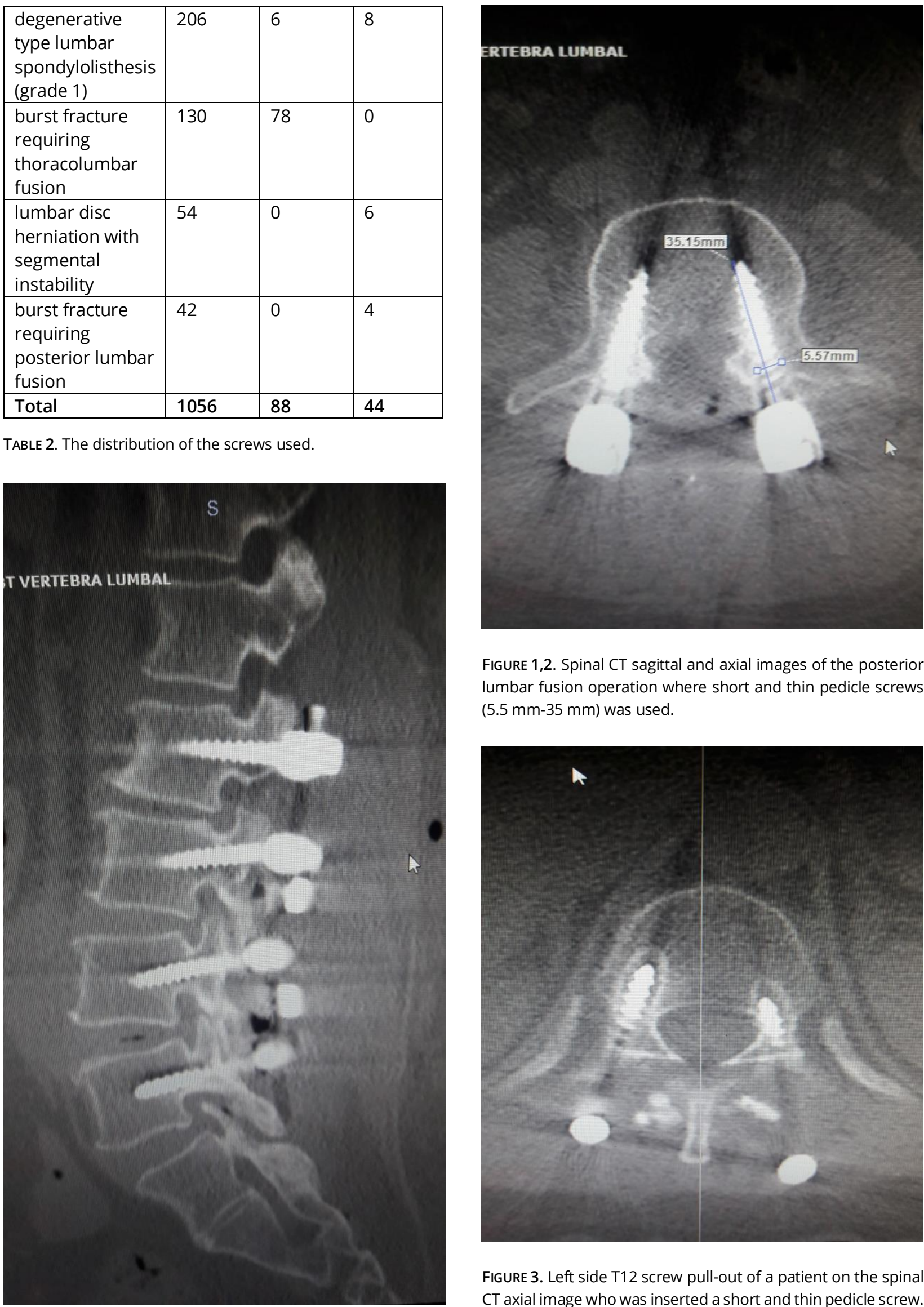

FIGURE 1,2. Spinal CT sagittal and axial images of the posterior lumbar fusion operation where short and thin pedicle screws (5.5 mm-35 mm) was used.

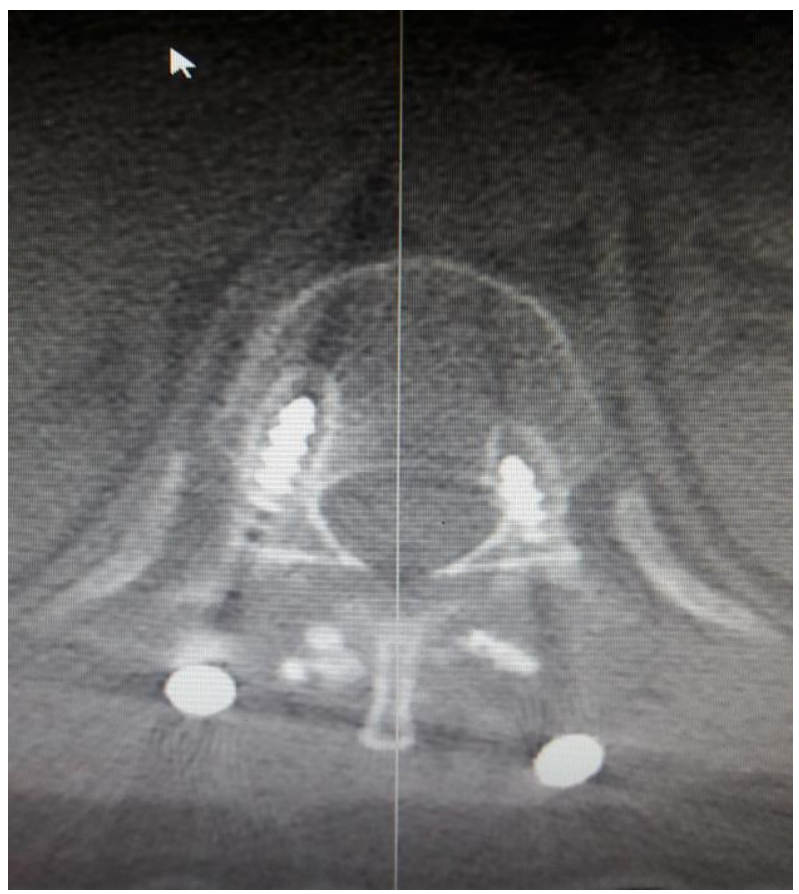

FIGURE 3. Left side T12 screw pull-out of a patient on the spinal CT axial image who was inserted a short and thin pedicle screw. 


\section{DISCUSSION}

The mechanisms preventing pull-out are thought to be large screw outer diameter, low screw inner diameter, short intergroove distance, and a strong bone structure. The most important of these has been shown to a large screw outer diameter. It is believed that a length that goes past the neurocentral junction is sufficient in terms of stability. However, pericortical and even bicortical screw lengths that markedly go past the neurocentral junction are used in practice $[2,4]$.

No significant correlation was found between the screw length and the force needed to create pull-out in the cadaver study of Diaremes et al. Bone density seemed to be a more important factor in their study [5].

Karami et al. compared the force needed to create pull-out in mid-body, pericortical and bicortical screws in their cadaver study. The force needed to create pull-out increased as the screw depth increased. However, a statistically significant difference was only found between mid-body and bicortical screws [7].

There are also studies reporting opposite results in the literature [5]. Our study provides the results of the pull-out evaluation of screws with a thickness of $5.5 \mathrm{~mm}$ and invasion depth of $35 \mathrm{~mm}$ that were used to go past the neurocentral junction.

There was no significant difference between our pull-out rates during 6-month follow-up after 5.5×35 $\mathrm{mm}$ short and thin pedicle screws were inserted and the results of long and thick pedicle screw use in the literature $[4,5,6]$. It is possible that long and thick screws will be more effective in terms of spine stability according to Denis' three-column theory $[3,8]$. However, all screws went past the pedicle length and neurocentral junction with short and thin pedicle screw use. The importance of short pedicle screws in terms of surgical safety increases when it is considered that spinal surgery makes up a significant part of neurosurgical practice and a large number of surgeries are performed by surgeons with various levels of experience. The anterior, antero-lateral and lateral areas of the pedicle screw application area are surrounded by arterial and venous structures with very high flow. Although rare, damage to these structures during the screw implantation stage carries a high mortality rate $[1,9,10,11]$. Most of these surgeries are elective and concern the spine and any mortality creates a difficult situation.

Vascular damage can occur at 3 different stages: pedicle probe implantation, tapping, and screw implantation $[10,11]$. We believe that using a $35 \mathrm{~mm}$ screw at the pedicle probe placement stage will improve surgical safety and may decrease the probability of invading the main vascular structures in case of lateral malposition.

According to the results of this study, we recommend short pedicle screw use in appropriate cases after considering the risk-benefit balance. Every patient needs to evaluated separately. Biomechanical studies can evaluate the stability of short pedicle screws more clearly. Our results indicate that the pull-out rates of short pedicle screws that reach the neurocentral junction are similar to those of long screws.

The critical point here is that each patient should be evaluated according to his/her spine characteristics and the length of the screw to be used should be chosen so as to reach the neurocentral junction during preoperative planning.

Using a $5.5 \mathrm{~mm}$ screw instead of a $6.0 / 6.5 \mathrm{~mm}$ screw makes it easier to stay within the pedicle boundaries. It decreases the risk of pedicle burst during screw implantation and allows the use of a thicker screw when revision is required. Our results indicate that the pull-out rate for $5.5 \mathrm{~mm}$ screws is similar to thicker screws. Specific planning may be required for each patient in the presence of comorbid situations such as advanced osteoporosis, scoliotic deformity and rheumatic diseases.

\section{CONCLUSION}

The use of a $5.5 \times 35 \mathrm{~mm}$ screw during posterior lumbar and thoracolumbar instrumentation and fusion operations is less invasive than using longer and thicker screws and the pull-out rates may be similar.

\section{REFERENCES}

1. Akinrinlola A, Brinster DR. Endovascular treatment of a malpositioned screw in the thoracic aorta after anterior spinal instrumentation: the screwed aorta. Vasc Endovascular Surg. 2013;47:555-557.

2. Chatzistergos P. E., Magnissalis E. A., Kourkoulis S. K. A parametric study of cylindrical pedicle screw design implications on the pullout performance using an experimentally validated finite-element model. Medical Engineering \& Physics.2010;32(2):145-154 
3. Cho W, Cho SK, Wu C. The biomechanics of pediclescrewbased instrumentation.J Bone Joint Surg Br. 2010 Aug;92(8):1061-5.

4. Daftari TK, Horton WC, Hutton WC. Correlations between screw hole preparation, torque of insertion, and pullout strength for spinal screws. J Spinal Disord. 1994;7:139-45

5. Diaremes $P$, Kokkinakis MC, Kurth AA, Kafchitsas K. The role of insertion length of pedicle screws on their pullout strength. A cadaveric study.Orthopaedic Proceedings 201193-B:SUPP_III, 366-366

6. Galbusera F, Volkheimer D, Reitmaier S, Berger-Roscher N, Kienle A, WilkeHJ. Pedicle screw loosening: a clinically relevant complication? Eur Spine J.2015May;24(5):1005-16. doi: 10.1007/s00586-015-3768-6.

7. Karami KJ, Buckenmeyer LE, Kiapour AM, Kelkar PS, GoelVK, DemetropoulosCK, Soo TM. Biomechanical evaluation of the pedicle screw insertion depth effect on screw stability under cyclic loading and subsequent pullout. J Spinal Disord Tech. 2015 Apr;28(3):E133-9.
8. Mehmanparast H, Petit $\mathrm{Y}$, Mac-Thiong JM. Comparison of pedicle screw loosening mechanisms and the effect on fixation strength. J Biomech Eng. 2015;137:121003

9. Mirza AK, Alvi MA, Naylor RM, Kerezoudis P, Krauss WE, Clarke MJ, Shepherd DL, Nassr A, DeMartino RR, Bydon M. Management of major vascular injury during pedicle screw instrumentation of thoracolumbar spine. ClinNeurol Neurosurg 2017;163:53-59

10. Wegener B, Birkenmaier C, Fottner A, et al. Delayed perforation of the aorta by a thoracic pedicle screw. Eur Spine J. 2008;17:S351-S354.

11. Zeiller SC, Lee J, Lim M, et al. Posterior thoracic segmental pedicle screw instrumentation: evolving methods of safe and effective placement. Neurol India. 2005;53:458-465.

12. Zhang $\mathrm{QH}$, Tan $\mathrm{SH}$, Chou SMM. Investigation of fixation screw pull-out strength on human spine. Journal of Biomechanics. 2004;37(4):479-485. doi: 10.1016/j.jbiomec h.2003.09.005. 